\title{
Major decrease in the incidence of trisomy 21 at birth in south Belgium: mass impact of triple test?
}

\author{
Alain Verloes ${ }^{1}$, Yves Gillerot ${ }^{2}$, Lionel Van Maldergem², Roland Schoos ${ }^{1}$, Christian Herens ${ }^{1}$, \\ Mauricette Jamar ${ }^{1}$, Vinciane Dideberg ${ }^{1}$, Sylviane Lesenfants ${ }^{1}$ and Lucien Koulischer ${ }^{1}$
}

\author{
${ }^{1}$ Wallonia Centre for Human Genetics, Liège University, Liège; ${ }^{2}$ Institut de Pathologie et de Génétique, Loverval, \\ Belgium
}

In South Belgium (Wallonia), the 'triple test' was introduced in 1990-1991, and is nowadays a widely accepted screening method for assessment of trisomy 21 risk in pregnancy. The 'triple test' is not regulated and can be freely performed by any biomedical lab, making epidemiological data unavailable. By contrast, cytogenetic investigations are limited to a few genetic centres, and accurate statistics can be easily built from their files. During the period 1984-1989, a total of 244 trisomy 21 (1/876 pregnancies) were diagnosed in the Genetic Centres of Liège and Loverval, $42(17 \%)$ of them prenatally. During the period 1993-1998, 294 trisomy 21 (1/704 pregnancies) were observed, 165 (56\%) of which prenatally, and more than $90 \%$ of affected pregnancies were terminated. Even after correction for late foetal loss of trisomic foetuses, the difference is highly significant, and corresponds to a theoretical shift in the incidence of trisomy 21 at birth from 1/794 to 1/1606. As no remarkable progress occurred in other non-invasive prenatal screening procedures or general health care policies in Belgium, the most reasonable explanation is the use on a large scale of triple test by pregnant women, and the election of termination for most affected pregnancies. European Journal of Human Genetics (2001) 9, 1-4.

Keywords: trisomy 21 incidence; triple test; prenatal diagnosis; epidemiology

\section{Introduction}

In many countries, prenatal screening for Down syndrome risk is now well established and almost a routine procedure. Commercial kits have been developed and the test is systematically offered to cohorts of pregnant women. During the second trimester, different maternal serum markers have been proposed: human chorionic gonadotrophin (HCG) or its variants (free $\beta$ HCG, core HCG), $\alpha$-foetoprotein (AFP) and unconjugated oestriol, these three markers forming the 'classic triple test'. During the first trimester, PAPP-A and free $\beta$ HCG are proposed; the latter can be combined with the study of nuchal translucency. The tripletest is not diagnostic: it gives an evaluation of the risk. If the risk is higher than a predetermined cut-off (varying from 1/250 to $1 / 350$ at time of birth), an invasive prenatal diagnosis, usually amniocentesis, is suggested. If the results show an affected foetus and the couple agrees, termination may be elected. Therefore, the

Correspondence: Professor Alain Verloes, CUWG, CHU-Sart Tilman, B 4000 Liège, Belgium. E-mail: Alain.Verloes@chu.ulg.ac.be Received 14 January 2000; revised 16 August 2000; accepted 13 September 2000 birth prevalence of trisomy 21 should tend to decrease (Spencer and Carpenter ${ }^{1}$ ).

Belgium is a federal kingdom, composed of three administrative regions with distinct governments (Flanders, Wallonia, and Brussels). Wallonia, the southern, French-speaking part of Belgium counts about 3.5 million inhabitants. Triple test was not performed in any laboratory in Belgium before 1 January 1990. It was introduced by our team in Wallonia in 1990, and was rapidly proposed to a large proportion of the pregnant women in South Belgium. The Genetic Centre of Liège offers the triple test using a locally developed dried blood technique (Verloes et $\mathrm{al}^{2}$ ) which is also commercially available (Gamma ${ }^{\circledR}$, Liège, Belgium). We perform about 13000 tests per year (Verloes et $\mathrm{al}^{3}$ ), ie roughly in $1 / 3$ of all pregnancies in Wallonia. In our laboratory, about $15 \%$ of the tests are performed during the first trimester of pregnancy. Cut-off risk has been set at $1 / 250$ at term. However, between $1 / 250$ and $1 / 350$ gynaecologists are invited to decide whether they advise amniocentesis or not. In Belgium, the practice of medicine is unrestricted and the triple test is not regulated. Hence, screening for trisomy 21 in maternal serum can be 
performed - and in practice is performed - by many public and private laboratories, without any particular control or restriction, and has been rapidly accepted as a routine procedure by most obstetricians. It is therefore impossible to know how many women actually undergo the test in Wallonia, which kits are used, when the test is requested (first or second trimester) and which cut-offs are used. Nevertheless, based on our local experience, we estimate that at least between two-thirds and three-quarters of pregnancies are screened.

In contrast to the free and widespread practice of triple test, cytogenetic investigations in Belgium are restricted to eight Human Genetic Centres, linked to medical schools, and recognised by federal decree. No private laboratory undertakes cytogenetic investigations. The centres perform all genetic analyses. As no diagnosis of trisomy 21 on any material (blood, amniotic fluid, chorionic villi, abortion material) is made outside the genetic centres, it is very easy to collect accurate data concerning all chromosome anomalies detected in Belgium during a given period, as the whole population is surveyed. In South Belgium, two genetic centres exists, in Liège and Loverval. Almost $99 \%$ of all births take place in hospital. A survey of maternities by our two centres in collaboration has shown that we roughly cover together $90 \%$ of all births in Wallonia. Hence the exact number of trisomies, detected either pre- or post-natally is precisely known.

The aim of the present study was to determine whether the use of large-scale triple test screening in South Belgium had a measurable impact on the epidemiology of trisomy 21 , by comparing the 6-year period preceding the implementation of the test with the 6-year period following it.

Although Wallonia is not an independent country, but a federal unit, the present study is closer to a national survey than a regional survey, because the 'borders' between the federal areas are really socially and culturally significant and allow population-based data analysis.

\section{Material and methods}

Data on trisomy 21 diagnoses of mothers living in Wallonia and children born in Wallonia, were collected in the genetic centres of Liège and Loverval.

Official statistics are available in Belgium for the whole country and separately for the three regions through the Institut National de Statistiques (INS). The actual total number of births is known up to 1995 and estimates are available for 1996-1998. Data have been published up to 1992 concerning the mother's age when giving birth (INS, 1996). ${ }^{4}$ Note that, because official statistical tables are continuously updated and edited, the number of pregnancies extracted from the INS 1996 reports (by maternal age), and those obtained in December 1999 (INS, unpublished data) and used in Table3, are slightly different from each other.
Since 1971, most pregnancies and births in Wallonia have been supervised for chromosome analysis by the genetic centres of Liège and Loverval and annual data and mode of diagnosis are available and regularly updated (Koulischer and Gillerot; ${ }^{5}$ Koulischer et $\mathrm{al}^{5}$ ).

Data on trisomy 21 gathered in our two laboratories have been split into two groups for analysis. The period from 1984 to 1989 (PRE) represents the 'pre-triple test era', when most amniocenteses were undertaken for maternal age or ultrasound anomalies. The triple test was implemented in South Belgium in 1990 and rapidly gained wide acceptance. Based on our own recruitment, the period 1990-1992 can be considered as the 'transition era'. The period from 1993 to 1998 inclusive is the post 'triple test era' (POST), during which the triple test has been widely offered in South Belgium and can be considered as the major modification in prenatal diagnosis strategies.

Because spontaneous foetal loss occurs during the second and third trimesters of pregnancy, the number of trisomic foetuses detected by CVS and amniocentesis is higher than the actual number of potential trisomic newbirths. Schreinemachers et $\mathrm{al}^{7}$ calculated this spontaneous loss to represent $1 / 5$ of the prenatally detected cases.

All statistics have been assembled using standard procedures, with the Statistica Package version 6 (Statsoft ${ }^{\circledR}$, Tulsa, USA) running on a PC.

\section{Results}

Based on our previous data on incidence of trisomy $21^{6}$ and on the population data from the INS, expected incidences at birth without any prenatal diagnosis have been computed (Table1) for 1987 (mid of the PRE era) and 1992 (last available data by maternal age), taking account of the maternal ages. Those incidences are close to 47 and 54, respectively.

Diagnoses of trisomy 21 made on blood, amniotic fluid cells (AF), or chorionic villi (CVS) between 1984 and 1998 are shown in Table 2 in absolute levels (using raw data and data corrected following Schreinemachers ${ }^{7}$ ) and in Figure 1 in relative proportions of pre- and postnatal diagnosed cases (using corrected values). Yearly fluctuations in absolute numbers are noteworthy: from 23 to 63 cases/year. The mean number of cases/year between 1984 and 1998 is 44.6, (SD:

Table 1 Anticipated trisomy (T21) births in South Belgium, based on demographic data from 1987 and 1992

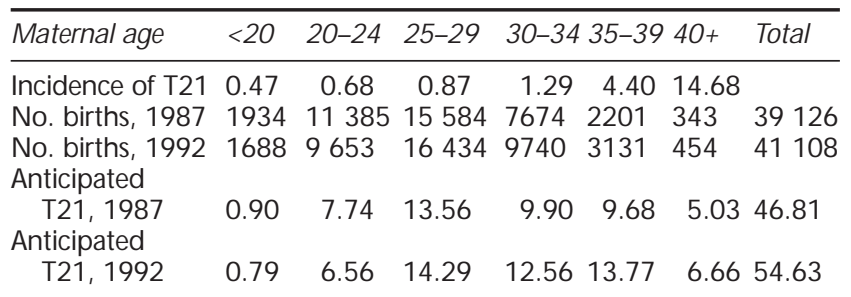


Table 2 Trisomy 21 (T21) diagnosed from 1984 to 1998 at birth, in amniotic fluid (AF) and chorionic villi samples (CVS) and percentage postnatally detected

\begin{tabular}{|c|c|c|c|c|c|c|c|c|c|c|c|}
\hline Year & Births & $\begin{array}{l}\text { T21 } \\
\text { newborns }\end{array}$ & $\begin{array}{l}\text { T21 } \\
\text { by AF }\end{array}$ & $\begin{array}{l}\text { T21 } \\
\text { by CVS }\end{array}$ & $\begin{array}{l}\text { Total } \\
\text { prenatal }\end{array}$ & $\begin{array}{l}\text { Corrected } \\
\text { prenatal }\end{array}$ & $\begin{array}{l}\text { Total } \\
\text { T21 }\end{array}$ & $\begin{array}{l}\text { Corrected } \\
\text { total }\end{array}$ & $\begin{array}{l}\text { Anticipated } \\
\text { number* }\end{array}$ & $\begin{array}{l}\text { Proportion } \\
\text { postnatal }\end{array}$ & $\begin{array}{l}\text { Corrected } \\
\text { proportion postnatal }\end{array}$ \\
\hline 1984 & 38038 & 20 & 6 & 0 & 6 & 4.8 & 26 & 24.8 & & 0.769 & 0.806 \\
\hline 1985 & 38356 & 34 & 1 & 1 & 2 & 1.6 & 36 & 35.6 & & 0.944 & 0.955 \\
\hline 1986 & 39511 & 30 & 4 & 1 & 5 & 4 & 35 & 34 & & 0.857 & 0.882 \\
\hline 1987 & 39628 & 34 & 8 & 0 & 8 & 6.4 & 42 & 40.4 & 42 & 0.810 & 0.842 \\
\hline 1988 & 40802 & 48 & 11 & 0 & 11 & 8.8 & 59 & 56.8 & & 0.814 & 0.845 \\
\hline 1989 & 41072 & 36 & 10 & 0 & 10 & 8 & 46 & 44 & & 0.783 & 0.818 \\
\hline 1990 & 41210 & 27 & 11 & 2 & 13 & 10.4 & 40 & 37.4 & & 0.675 & 0.722 \\
\hline 1991 & 42189 & 31 & 6 & 2 & 8 & 6.4 & 39 & 37.4 & & 0.795 & 0.829 \\
\hline 1992 & 41177 & 34 & 17 & 1 & 18 & 14.4 & 52 & 48.4 & 49 & 0.654 & 0.702 \\
\hline 1993 & 39397 & 22 & 17 & 4 & 21 & 16.8 & 43 & 38.8 & & 0.512 & 0.567 \\
\hline 1994 & 37905 & 13 & 32 & 0 & 32 & 25.6 & 45 & 38.6 & & 0.289 & 0.337 \\
\hline 1995 & 37586 & 21 & 30 & 0 & 30 & 24 & 51 & 45 & & 0.412 & 0.467 \\
\hline 1996 & 38497 & 26 & 20 & 0 & 20 & 16 & 46 & 42 & & 0.565 & 0.619 \\
\hline 1997 & 38584 & 18 & 28 & 0 & 28 & 22.4 & 46 & 40.4 & & 0.391 & 0.446 \\
\hline 1998 & 38326 & 29 & 34 & 0 & 34 & 27.2 & 63 & 56.2 & & 0.460 & 0.516 \\
\hline
\end{tabular}

Raw data and values corrected for spontaneous fetal death (-20\%) are given. As a test for completion of the data collection, the actual number of trisomies observed in 1987 and 1992 is compared with the anticipated number*, which represents 90\% of the number of trisomies computed in Table 1.

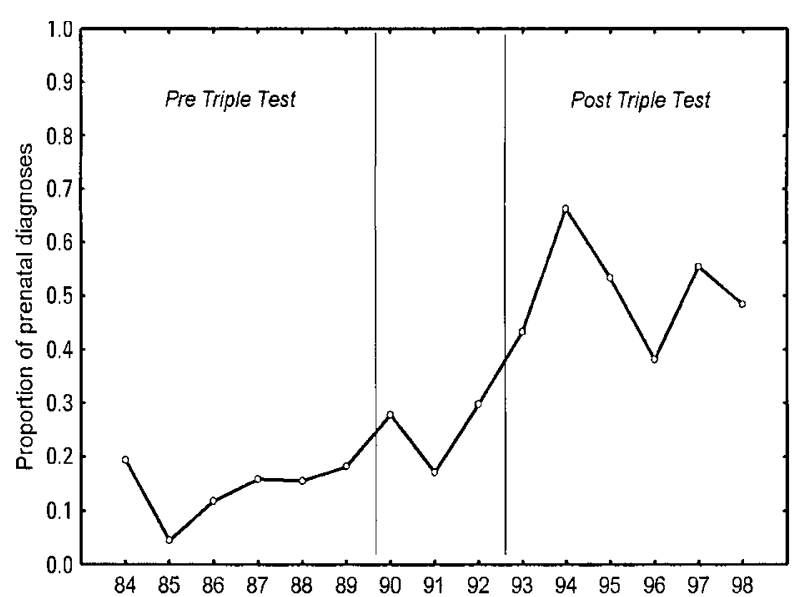

Figure 1 Relative frequencies of prenatal vs postnatal diagnosis of trisomy 21 in South Belgium, 1984-1998 (corrected values).

9.3-95\% confidence interval : 39.4-49.8). Accounting for spontaneous loss, the expected number of trisomic newborns would have been $41.3 /$ year. (SD: $8.2-95 \% \mathrm{Cl}$ : 36.8-45.9) in the interval 1984-1998. For 1987 and 1992, the observed values are not significantly different from the values extrapolated from maternal ages, thus confirming our high ascertainment ratio. Interestingly, most prenatally diagnosed trisomies have been terminated. For some pregnancies, the outcome was not available, but on a total of 207 prenatal diagnoses, we are aware of more than 190 abortions. We estimate with confidence that $90-95 \%$ of prenatally diagnosed trisomies are aborted.

Regression of the proportion of prenatally diagnosed cases (corrected values) on decimal year for the full set and, separately, for the PRE and POST periods, show that the slope is significantly different from 0 for the whole set $(P<0.01)$, whereas is not significantly different from 0 (Table 3 ) for each subset.

Table 4 shows basic statistics and comparisons between the PRE and POST periods. There is a trend to an increase in the total number of trisomies 21 , although the difference in mean number of trisomies is not significant when PRE and POST are compared. A highly significant difference is observed between the two periods when the absolute numbers or the proportion of prenatal diagnoses are compared. Table 4 also shows incidence of trisomy 21 (with or without correction) and its theoretical incidence at birth (assuming systematic termination) in Wallonia, for the PRE and POST periods.

\section{Discussion}

When an ultrasound scan is used to estimate gestational age the detection rate for a $5 \%$ false-positive rate is estimated to be $59 \%$ using the double test (AFP and hCG), 69\% using the triple test (AFP, hCG, uE3) (Wald et $\mathrm{al}^{8}{ }^{8}$ ). This goal has been almost achieved 'spontaneously' in Wallonia, where no systematic screening has ever been organised, and different techniques are used. In our population, the mean (corrected) incidence of trisomy 21 was 1/906 and 1/794 for the PRE and

Table 3 Decline and its limits in the regression of the proportion of prenally diagnosed foetuses (corrected values) to the year (in decimals) for the whole period, the PRE period and the POST period

\begin{tabular}{|c|c|c|c|c|c|}
\hline & Slope & $\begin{array}{l}\text { Inferior limit } \\
(\mathrm{P}=0.99)\end{array}$ & $\begin{array}{l}\text { Inferior limit } \\
(P=0.95)\end{array}$ & $\begin{array}{l}\text { Superior limit } \\
(P=0.95)\end{array}$ & $\begin{array}{l}\text { Superior limit } \\
(P=0.99)\end{array}$ \\
\hline Full set & 0.0355 & 0.0171 & 0.0223 & 0.0487 & 0.0539 \\
\hline PRE & 0.0089 & -0.0545 & -0.0294 & 0.0472 & 0.0724 \\
\hline POST & -0.0064 & -0.1276 & -0.0795 & 0.0667 & 0.1148 \\
\hline
\end{tabular}


Table 4 Comparison of the detection rate of T21 in the periods 1984-1989 and 1993-1998

\begin{tabular}{|c|c|c|c|c|}
\hline & & PRE (1984-1989) & POST (1993-1998) & P level \\
\hline \multirow[t]{3}{*}{ Number of T21 } & Raw & 244 & 294 & \\
\hline & Corrected & 235.6 & 261 & \\
\hline & Not detected & 202 & 129 & \\
\hline Population ${ }^{a}$ & & 213666 & 207265 & \\
\hline \multirow[t]{2}{*}{ Detection rate } & Raw & $17 \%$ & $56 \%$ & $<0.0001$ \\
\hline & Corrected & $14 \%$ & $50.6 \%$ & $<0.0001$ \\
\hline Total/year $\pm S D$ & Raw & $40.7 \pm 11.3$ & $49 \pm 7.3$ & 0.16 \\
\hline \multirow[t]{2}{*}{ Prenatal/year $\pm \mathrm{SD}$} & Raw & $7 \pm 3.3$ & $27.5 \pm 5.8$ & 0.00002 \\
\hline & Corrected & $5.6 \pm 2.7$ & $22 \pm 4.6$ & 0.00002 \\
\hline \multirow[t]{3}{*}{ Incidence } & Raw & $11.410^{-4} \quad(1 / 876)$ & $14.210^{-4} \quad(1 / 704)$ & \\
\hline & Corrected & $1110^{-4} \quad(1 / 906)$ & $12.610^{-4} \quad(1 / 794)$ & \\
\hline & Not detected & $9.410^{-4}(1 / 1058)$ & $6.210^{-4}(1 / 1606)$ & \\
\hline
\end{tabular}

Data are \pm 1 SD. Raw and corrected values (which reduce the actual number of prenatally diagnosed cases) are included. (P levels are based on the $\mathrm{t}$ values for each comparison. atotal number of births corresponds to $90 \%$ of the total number of births in Wallonia (see Introduction).

the POST periods, respectively. This increase appears linked to an increased mean maternal age, as observed between 1987 and 1992. The observed incidences of trisomy diagnosed at birth during the same periods are 1/1058 and $1 / 1606$, respectively, corresponding to a shift of $14 \%$ to $50.6 \%$ in the detection rate. Figure 1shows that the decline is not the result of a continuous trend, but rather that the PRE and POST periods had different but stable detection rates. As no remarkable progress occurred in other non-invasive prenatal screening procedures (e.g. ultrasound) or general health care policies in Belgium between 1990 and 1992, the most reasonable explanation is the use on a large scale of the triple test followed by amniocentesis of pregnant women, and election to terminate most affected pregnancies. Interestingly, in our region, CVS which was common practice in the late 1980s has gradually disappeared as a routine cytogenetic procedure, and is now restricted to specific indications with high recurrence risks (parental translocations, biochemical or molecular diagnoses of Mendelian disorders).

A remarkable point is the huge variation in the yearly number of trisomies. The most likely hypothesis is that these variations are stochastic fluctuations associated with the small numbers involved. At least, it shows the usefulness of using the data obtained during a short period of time, and makes the estimation of the proportion of prenatal diagnosis a better indicator that the absolute number of cases, which depend on demographic fluctuations, as illustrated in Table 1 , which shows that, in a short lapse of time (5 years), a significant increase in the older age group has occurred.
It is to be expected that the use of new serum markers and the routine measurement of nuchal translucency in the first trimester of pregnancy will contribute to an increase in the antenatal detection rate of trisomy 21 in the future.

\section{Acknowledgements}

We would like to thank our social workers, M rs M Lefèvre (Loverval) and $M-T$ Parent (Liège) for their help in the preparation of this manuscript.

\section{References}

1 Spencer K, Carpenter P: Risk of Down's syndrome and anmiocentesis rate. BMJ 1992; 304: 640-641.

2 Verloes A, Schoos R, Koulischer L: Non-radioactive assay of AFP, hCG, and uE3 from dried blood specimens: a low-cost alternative for maternal screening for trisomy 21. Prenat Diagn 1992; 12: 1073-1074.

3 Verloes A, Schoos R, Herens C, Vintens A, Koulischer L: A prenatal trisomy 21 screening program using alpha-fetoprotein, human chorionic gonadotropin, and free estriol assays on maternal dried blood. Am J Obstet Gynecol 1995; 72: 167-174.

4 Institut National de Statistiques: Statistiques démographiques 1996, vol 2. Ministè Belge des Affaires économiques, 1996.

5 Koulischer L, Gillerot Y: Down's syndrome in Wallonia (South Belgium), 1971-1978: cytogenetics and incidence. Hum Genet 1980; 54: 243-250.

6 Koulischer L, Gillerot Y, Lefèvre M, Lami M, Mancuso S: Down syndrome: prenatal diagnosis and incidence at birth. A 20-year study in Belgium. Am J Hum Genet 1991; 49: (suppl.) 267.

7 Schreinemachers DM, Cross PK, Hook EB: Rates of trisomies21, 18 , 13 and other chromosome abnormalities in about 20000 prenatal studies compared with estimated rates in live births. Hum Genet 1982; 61: 4, 318-324.

8 Wald NJ, Kennard A, Hackshaw A, McGuire A: Antenatal screening for Down's syndrome. J Med Screen 1997; 4: 181-246. 